\title{
Efeitos de um derrame experimental de óleo bunker na sobrevivência e taxas de crescimento de plântulas de Laguncularia racemosa (Combretaceae)
}

\author{
Emanoela Nardes \\ Maurício Garcia de Camargo * \\ Paulo Cunha Lana \\ Laboratório de Modelagem Ecológica, Centro de Estudos do Mar, Universidade Federal do Paraná Caixa Postal 61, \\ CEP 83255-976, Pontal do Paraná - PR, Brasil \\ * Autor para correspondência \\ camargo.ufpr@gmail.com \\ Submetido em 30/11/2011 \\ Aceito para publicação em 05/11/2012
}

\section{Resumo}

Os efeitos do óleo bunker na sobrevivência e nas taxas de crescimento de Laguncularia racemosa foram testados por meio de um experimento de derrame controlado, aplicado em 60 plântulas individualmente plantadas em pequenos sacos plásticos. A cada uma destas unidades experimentais foi atribuído um dos seis tratamentos: 0mL (controle), 10, 20 30, 40 e $50 \mathrm{~mL}$ de óleo bunker derramado em cada saco. O experimento foi monitorado semanalmente durante 20 semanas. Os resultados foram analisados por ANOVA de medidas repetidas e regressão linear. Nas primeiras sete semanas foram observadas clorose, perda de folhas e taxa de mortalidade significativamente superior para as plantas de todos os tratamentos em comparação com o grupo controle. Efeitos crônicos como prejuízos ao crescimento e produção de folhas foram proporcionais às concentrações de óleo dos tratamentos. As plântulas dos tratamentos controle e $10 \mathrm{~mL}$ foram significativamente superiores aos demais tratamentos em altura, número de folhas e nível de vitalidade. Os resultados indicaram que as plântulas de L. racemosa sofrem efeitos letais e subletais com a exposição ao óleo bunker.

Palavras chave: Hidrocarbonetos; Impacto; Mangue-branco

\section{Abstract}

Effects of an experimental oil spill (bunker) on seedling survival and growth rate of Laguncularia racemosa (Combretaceae). The effects of bunker oil on survival and growth rate of Laguncularia racemosa were tested using 60 seedlings planted in small plastic bags (experimental unit). One of the six treatments was randomly assigned to each bag: $0 \mathrm{~mL}$ (control), $10 \mathrm{~mL}, 20 \mathrm{~mL}, 30 \mathrm{~mL}, 40 \mathrm{~mL}$ e $50 \mathrm{~mL}$ of bunker oil spilled in each bag. The experiment was monitored weekly for 20 weeks. The results were analyzed by repeated measure ANOVA and linear regression. In the first seven weeks, we observed chlorosis, loss of leafs and death rate significantly superior to plants of all treatments compared to the control group. Persistent effects like reduction of stem growth and leaf production was proportional to the initial oil concentration. The plants from control and $10 \mathrm{~mL}$ treatments were significantly superior to all remaining treatments in height, leaf number and healthy level. Results indicated that L. racemosa seedlings suffer both lethal and sublethal effects from exposition to bunker oil exposure.

Key words: Hydrocarbons; Impact; White mangrove 


\section{Introdução}

Os efeitos do petróleo e seus derivados nos manguezais vêm sendo investigados há mais de 40 anos através de experimentos de campo e laboratório, além de observações diretas de derrames acidentais (NOAA, 2003). A maioria destes estudos demonstra que o óleo prejudica ou mata as árvores de mangue. O que é menos óbvio é como estes danos ocorrem e os mecanismos de toxicidade envolvidos (NRC, 2003).

Há o consenso entre os pesquisadores de que o óleo causa sufocamento físico e impactos fisiológicos e toxicológicos em plantas de mangue, mas o maior desafio para a ciência é descobrir qual a contribuição relativa destes mecanismos sobre os efeitos observados e a variação na resposta das plantas de acordo com diferentes tipos de derivados de petróleo, além dos efeitos das variáveis ambientais no tamanho do impacto causado por um derrame (NOAA, 2002).

Em contato com o óleo, árvores adultas e juvenis podem sofrer intensa perda de folhas e consequente morte nas primeiras semanas, efeitos estes considerados letais ou agudos (GRANT et al., 1993). Efeitos subletais ou crônicos como anomalias nos pneumatóforos, lenticelas e tronco, declínio na produção de folhas, prejuízos à reprodução, redução do tamanho das folhas, mutações e, no caso dos juvenis, prejuízos ao estabelecimento e irregularidades no crescimento ocorrem após o primeiro mês (PROFFIT; DEVLIN, 1998).

Os efeitos agudos e crônicos variam de acordo com o tipo de planta e de óleo envolvido. Laguncularia racemosa é mais sensível do que Rhizophora mangle (TOUCHETTE et al., 1992), juvenis são mais sensíveis do que plantas já estabelecidas (IMBERT et al., 2000) e óleos leves são mais tóxicos que os óleos densos (DUKE et al. 2000).

Cada tipo de óleo sofre diferentes efeitos dos processos de intemperização (VOLKMAN et al. 1992), que modificam de forma única sua composição e definem o tipo de impacto que seus compostos causarão ao ambiente (BURNS; SIMMONS, 1994).

De acordo com a densidade e propriedades específicas, os diferentes tipos de óleo bruto e derivados foram classificados pela NOAA (2003) em quatro categorias: super leves (combustíveis de avião e gasolina); leves (óleo diesel, óleo combustível no 2 e brutos leves); médios (maioria dos óleos brutos) e densos (bunker $\mathrm{C}$, óleo combustível ํㅡ 6 e brutos densos).

O óleo bunker é um combustível de navios que possui baixa solubilidade devido à sua grande densidade, propriedade que o torna menos tóxico. Seus efeitos agudos (letais e em curto prazo) são, portanto, causados principalmente pelo contato direto do óleo com as folhas, pneumatóforos e lenticelas das árvores, prejudicando seus mecanismos de sobrevivência nos manguezais (NRC, 2003). Quando as folhas e pneumatóforos são recobertos por óleo denso, as plantas de mangue têm seus processos biológicos de troca com o ambiente reduzidos, especialmente a fotossíntese e a respiração (PEZESHKI et al., 2000).

A grande densidade do óleo bunker lhe confere as propriedades de alta emulsificação, baixa evaporação e intemperização lenta, que fazem com que permaneça longamente no sedimento e que seus componentes fiquem disponíveis para bioacumulação e biomagnificação (efeitos crônicos) (NOAA, 2003; NUDI et al., 2007).

A presença de anéis de benzeno na composição do óleo bunker, principalmente hidrocarbonetos policíclicos aromáticos (PAH) (WANG et al., 1999), representa perigo adicional para o meio ambiente, pois estes são muito estáveis e persistentes, podem ter efeitos tóxicos e deletérios nos organismos, danificar tecidos e, em elevadas concentrações no sedimento, produzir mutações de deficiência de clorofila em plantas de mangue (NRC, 2003).

O objetivo deste trabalho é avaliar as taxas de mortalidade, crescimento, produção de folhas e vitalidade de plântulas de Laguncularia racemosa cultivadas em viveiro e submetidas a derrames experimentais agudos de óleo bunker.

Estudos desta natureza ajudam a preencher as lacunas existentes no conhecimento das respostas biológicas das plantas de mangue a derrames de óleo e podem auxiliar na proposição de técnicas mais eficazes de recuperação e remediação (LEWIS, 2005; BRITO et al., 2009). 


\section{Material e Métodos}

Os efeitos do óleo bunker MF-380 em plântulas de Laguncularia racemosa foram testados por meio de derrame experimental único (agudo) e monitorados por 20 semanas.

Foram coletadas, diretamente do manguezal do rio Perequê em Pontal do Sul (PR), 120 plântulas de Laguncularia racemosa, todas com cerca de 20 dias de vida (cotilédones abertos e bem desenvolvidos). Cada uma foi plantada em um saco de muda com dimensões de 14 x 18 com $800 \mathrm{~g}$ de sedimento natural homogeneizado. As mudas foram então estocadas em um viveiro coberto com proteção solar (sombrite 50\%) e acomodadas em bancadas protegidas contra herbivoria.
As plântulas receberam rega com água da gamboa adjacente ao manguezal de origem até completarem 70 dias, quando apresentaram pelo menos duas folhas verdadeiras. Destas, as 60 mudas com aparência mais saudável foram selecionadas para a realização do experimento.

Cada uma das 60 plântulas foi designada aleatoriamente a cada um dos seis tratamentos deste estudo, perfazendo 10 réplicas. Os tratamentos consistiram no derrame de crescentes quantidades de óleo sobre as plântulas $(0,10,20,30,40$ e $50 \mathrm{~mL})$. As plântulas foram medidas e apresentaram alturas semelhantes (cerca de $6 \mathrm{~cm} / \mathrm{semana}$ zero na Figura 1) e posteriormente o óleo bunker foi derramado em cada plântula apenas uma vez (derrame agudo), atingindo as folhas, caule e sedimento. Para o derrame foi utilizada uma seringa de $60 \mathrm{~mL}$ a uma distância de $5 \mathrm{~cm}$ das folhas superiores.

FIGURA 1: Altura (em cm) de plântulas de L. racemosa ( \pm erro padrão) em função dos seis tratamentos experimentais (de 0 até $50 \mathrm{~mL}$ de óleo bunker derramado) e do tempo em semanas. A legenda mostra a concentração de óleo dos tratamentos em uma escala de cores, desde o controle $(0 \mathrm{~mL})$ em rosa claro até a maior concentração $(50 \mathrm{~mL})$ em preto.

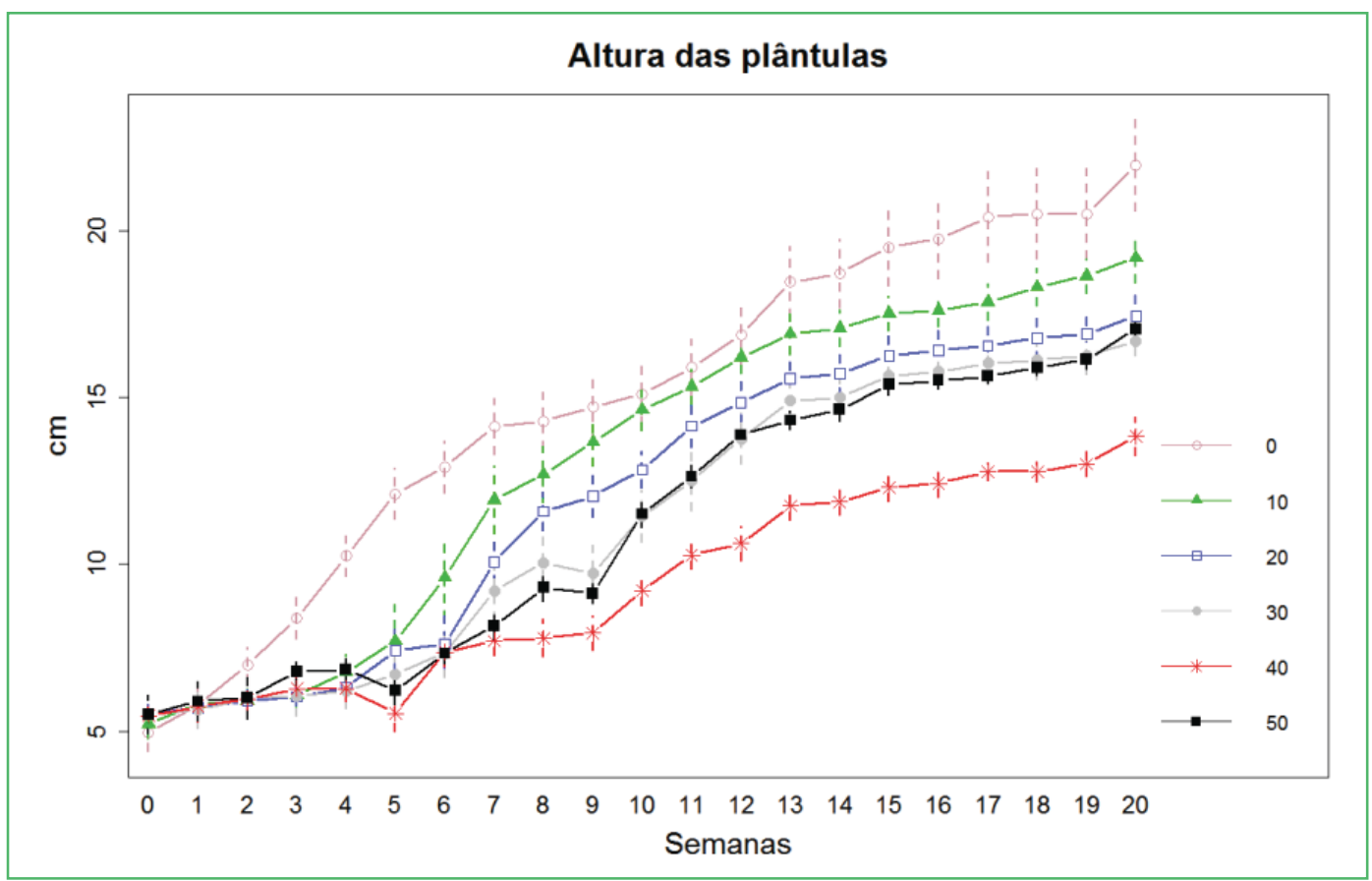


Uma escala de qualidade das plantas denominada "Nível de Vitalidade (NV)" foi construída através da combinação de todas as variáveis consideradas neste estudo (altura, diâmetro, comprimento, largura e número de folhas). $\mathrm{O}$ índice consiste numa escala dos seis níveis de vitalidade possíveis através dos quais a planta pode passar após o contato com óleo. O Nível de vitalidade representa uma tentativa de avaliar o estado geral das plantas durante o experimento e a sua construção é detalhada na Tabela 1.

O nível máximo de vitalidade é dado pelo número 6, quando a planta se apresenta aparentemente saudável, seguido pelos níveis 5, 4 e 3, quando os efeitos do óleo se manifestam crescentemente por meio de clorose (folhas amareladas), perda das folhas, perda de vitalidade e prejuízos ao crescimento do indivíduo. No nível 2, a planta apresenta apenas uma folha ou está com a maioria delas comprometidas, evoluindo daí para a inviabilidade, representada pelo nível 1 .

Altura, comprimento, largura e número de folhas, nível de vitalidade e diâmetro foram as variáveis dependentes, medidas semanalmente com auxilio de trena (para as três primeiras variáveis) e paquímetro (para a última variável) e monitoradas por 20 semanas.

Cada variável dependente foi analisada usando two-way ANOVA por medidas repetidas em um modelo linear misto com dois fatores ortogonais, tratamentos (fixo, com seis níveis) e tempos (aleatório, com 20 níveis). Comparações a posteriori foram efetuadas entre os tratamentos através do teste de SNK (UNDERWOOD, 1997) e entre os tempos através do teste de Scott-Knott, mais apropriado para grande número de níveis a serem comparados (SCOTT; KNOTT, 1974).

As tendências dos seis tratamentos experimentais ao longo das 20 semanas do estudo foram avaliadas estatisticamente para as variáveis dependentes que apresentaram relação linear (altura e diâmetro da plântula, número e comprimento das folhas), através do ajuste a um modelo linear regressivo e posterior inferência sobre os coeficientes angulares de regressão resultantes por meio do método descrito em Zar (1996). O teste consiste na comparação da inclinação de duas retas (b) partindo da hipótese nula de que as retas possuem a mesma inclinação.

TABELA 1: Nível de vitalidade (NV): escala de qualidade que combina as principais variáveis e aponta seis níveis pelos quais a planta pode passar após o contato com óleo. O nível 6 representa vitalidade e o 1 a morte da plântula. Cada nível é dividido em duas partes para diferenciar os quatro meses iniciais das plântulas dos demais meses, onde os efeitos aparecem de maneiras distintas.

\begin{tabular}{|c|c|}
\hline 6 & $\begin{array}{l}\text { Até } 4 \text { meses de vida (segundo mês de experimento): presença de no mínimo quatro folhas, planta ereta, sem } \\
\text { indícios de herbivoria (necrose) ou fungos, folhas livres (não grudadas entre si pelo óleo) verdes, lisas e brilhantes, } \\
\text { permitida a ausência de cotilédones após } 100 \text { dias de vida. } \\
\text { Após } 4 \text { meses: todas as informações acima + presença de mais de quatro folhas saudáveis. }\end{array}$ \\
\hline 5 & $\begin{array}{l}\text { Até } 4 \text { meses: presença de no mínimo quatro folhas e uma folha amarelada ou murcha ou com pontos de necrose } \\
\text { ou atrofia leve do caule ou das folhas em desenvolvimento. } \\
\text { Após } 4 \text { meses: presença de apenas quatro folhas saudáveis. }\end{array}$ \\
\hline 4 & $\begin{array}{l}\text { Até } 4 \text { meses: presença de apenas três folhas ou duas folhas amareladas ou murchas ou uma par de folhas grudadas } \\
\text { entre si ou clara atrofia do caule ou das folhas em desenvolvimento ou necrose em mais de } 1 \text { folha. } \\
\text { Após } 4 \text { meses: presença de apenas três folhas saudáveis ou atrofia do caule. }\end{array}$ \\
\hline 3 & $\begin{array}{l}\text { Até } 4 \text { meses: presença de apenas duas folhas ou três folhas amareladas ou murchas ou } 2 \text { pares de folhas } \\
\text { grudadas ou indícios de comprometimento do caule por necrose ou atrofia acentuada do caule ou das folhas em } \\
\text { desenvolvimento. } \\
\text { Após } 4 \text { meses: presença de apenas duas folhas saudáveis ou atrofia acentuada do caule. }\end{array}$ \\
\hline 2 & Presença de apenas uma folha ou todas as folhas murchas ou comprometimento do caule por necrose. \\
\hline 1 & as as folhas, morte. \\
\hline
\end{tabular}


Todas estas análises foram realizadas no ambiente R (R DEVELOPMENT CORE TEAM, 2011). Para as ANOVA e os testes SNK foi usado o pacote GAD (SANDRINI-NETO; CAMARGO, 2011) e para as comparações entre inclinações de retas de regressão foi usada uma função baseada nas fórmulas fornecidas por Sokal e Rohlf (1995).

\section{Resultados}

Os resultados de ANOVA por medidas repetidas e do teste a posteriori SNK para as variáveis selecionadas são sumarizados na Tabela 2.

TABELA 2: ANOVA por medidas repetidas e testes a posteriori SNK entre os tratamentos e Scott-Knott entre tempos (semanas) para variáveis dependentes selecionadas. Tempos (Te) é um fator aleatório com 20 níveis e Tratamentos (Tr) é um fator fixo com seis níveis. O teste SNK mostra os resultados dos seis tratamentos $(0 \mathrm{~mL}$ a $50 \mathrm{~mL}) \mathrm{em}$ ordem decrescente de média. O teste de Scott-Knott mostra as semanas agrupadas ( 0 a 20), encerradas entre as barras.

\begin{tabular}{|c|c|c|c|c|c|}
\hline \multicolumn{3}{|c|}{ Altura } & \multicolumn{3}{|c|}{ Largura das folhas } \\
\hline Tempos (Te) & $F=45,7$ & $\mathrm{p}<0,001$ & Tempos (Te) & $\mathrm{F}=4,24$ & $\mathrm{p}<0,001$ \\
\hline Tratamentos (Tr) & $F=3,78$ & $\mathrm{p}=0,003$ & Tratamentos (Tr) & $\mathrm{F}=13,28$ & $\mathrm{p}<0,001$ \\
\hline \multicolumn{3}{|c|}{$\begin{array}{l}\text { SNK }(\text { Entre tratamentos }) \\
(0=10=20)>(30=40)>50\end{array}$} & \multicolumn{3}{|c|}{$\begin{array}{c}\text { SNK }(\text { Entre tratamentos }) \\
0>(30=50=20=10)>40\end{array}$} \\
\hline \multicolumn{3}{|c|}{$\begin{array}{l}\text { Scott-Knott (Entre semanas) } \\
012|34| 5|6| 7|89| 10|11| 12|13 \quad 14| 15 \quad 16|17 \quad 1819| 20\end{array}$} & \multicolumn{3}{|c|}{$\begin{array}{l}\text { Scott-Knott (Entre semanas) } \\
0|1234| 567|891011 \quad 12| 131415 \quad 16 \mid 17181920\end{array}$} \\
\hline \multicolumn{3}{|c|}{ Diâmetro } & \multicolumn{3}{|c|}{ Número de folhas } \\
\hline Tempos (Te) & $F=33,30$ & $\mathrm{p}<0,001$ & Tempos (Te) & $\mathrm{F}=22,8$ & $\mathrm{p}<0,001$ \\
\hline Tratamentos (Tr) & $\mathrm{F}=2,96$ & $\mathrm{p}=0,014$ & Tratamentos (Tr) & $F=7,59$ & $\mathrm{p}<0,001$ \\
\hline \multicolumn{3}{|c|}{$\begin{array}{l}\text { SNK }(\text { Entre tratamentos }) \\
0>(30=50=20=10)>40\end{array}$} & \multicolumn{3}{|c|}{$\begin{array}{l}\text { SNK }(\text { Entre tratamentos }) \\
0>(10=20=30=50=40)\end{array}$} \\
\hline \multicolumn{3}{|c|}{$\begin{array}{l}\text { Scott-Knott (Entre semanas) } \\
0|12| 3456|7| 8910|1112| 13141516 \mid 17181920\end{array}$} & \multicolumn{3}{|c|}{$\begin{array}{l}\text { Scott-Knott (Entre semanas) } \\
0|1| 2345|6| 789|101112| 13141516 \mid 17181920\end{array}$} \\
\hline \multicolumn{3}{|c|}{ Comprimento } & \multicolumn{3}{|c|}{ Nível de Vitalidade (NV) } \\
\hline Tempos (Te) & $\mathrm{F}=17,71$ & $\mathrm{p}<0,001$ & Tempos (Te) & $\mathrm{F}=2,19$ & $\mathrm{p}<0,001$ \\
\hline Tratamentos (Tr) & $\mathrm{F}=3,42$ & $\mathrm{p}=0,006$ & Tratamentos (Tr) & $\mathrm{F}=40,08$ & $\mathrm{p}<0,001$ \\
\hline \multicolumn{3}{|c|}{$\begin{array}{l}\text { SNK }(\text { Entre tratamentos }) \\
(30=0=20=50=10)>40\end{array}$} & \multicolumn{3}{|c|}{$\begin{array}{l}\text { SNK }(\text { Entre tratamentos }) \\
0>10>(30=20=40)>50\end{array}$} \\
\hline \multicolumn{3}{|c|}{$\begin{array}{l}\text { Scott-Knott (Entre semanas) } \\
0|12345| 6789|1011| 12|13141516| 17181920\end{array}$} & \multicolumn{3}{|c|}{ Scott-Knott (Entre semanas) } \\
\hline
\end{tabular}


Resumidamente, as plântulas do tratamento controle apresentaram valores significativamente superiores de sobrevivência e crescimento ao longo do experimento em relação aos demais tratamentos para todas as variáveis (Tabela 2) (Figuras 1 a 8 ). De um modo geral, as plântulas dos tratamentos de $10 \mathrm{~mL}$ e 20 $\mathrm{mL}$ apresentaram valores mais próximos do controle $(0$ $\mathrm{mL}$ ) do que aquelas de tratamentos mais concentrados (30 a $50 \mathrm{~mL}$ ) (Figuras 9 a 11 e Tabela 3).

\section{Mortalidade}

Nas primeiras sete semanas foi observada taxa de mortalidade de $60 \%$ nas plântulas tratadas com $50 \mathrm{~mL}$ de óleo, enquanto as plântulas dos tratamentos 40, 30, 20 e $10 \mathrm{~mL}$ tiveram taxa de mortalidade de 40, 20, 40 e $20 \%$, respectivamente e o controle não apresentou mortes de plântulas.

Embora as taxas de mortalidade das plântulas dos tratamentos de maior concentração $(50 \mathrm{~mL})$ em alguns casos se igualem com as dos tratamentos de menor concentração (40 e $20 \mathrm{~mL}$, por exemplo), a observação das demais variáveis demonstra que as plântulas sobreviventes que receberam concentrações superiores de óleo tiveram mais prejuízos do que as demais.

As taxas de mortalidade observadas nas primeiras sete semanas se mantiveram iguais até o final do experimento, com sobrevivência significativamente superior para as plântulas do controle do que para as dos outros tratamentos.

\section{Altura}

Na primeira semana de experimento (semana zero/ Figura 1), antes do derrame de óleo, todas as plântulas foram medidas e apresentaram alturas semelhantes (cerca de $6 \mathrm{~cm}$ ).

As plântulas do tratamento controle apresentaram altura significativamente superior às dos demais tratamentos a partir da segunda semana e as do tratamento $10 \mathrm{~mL}$ tiveram altura significativamente superior às dos tratamentos de maior concentração a partir da semana seis, com exceção da semana 8 (Figura 1). Da oitava semana até a $11^{\text {a }}$ as plântulas do tratamento
$20 \mathrm{~mL}$ tiveram altura significativamente superior às dos tratamentos de maior concentração.

Os ajustes lineares das alturas em três tratamentos $(0 \mathrm{~mL}, 20 \mathrm{~mL}$ e $40 \mathrm{~mL})$ da Figura 2 demonstraram que o controle apresentou uma inclinação de reta mais pronunciada do que no tratamento de $40 \mathrm{~mL}$ (marginalmente significante).

FIGURA 2: Ajustes lineares das alturas das plântulas $(\mathrm{em} \mathrm{cm}) \mathrm{de}$ L. racemosa ( \pm erro padrão) em três dos tratamentos experimentais. A figura mostra ambos os eixos escalonados em zero para melhor demonstrar a diferença de inclinação da reta (b) entre os tratamentos de $0 \mathrm{~mL}$ (controle), $20 \mathrm{mLe} 40 \mathrm{~mL}$. Apesar da grande discrepância entre os valores, houve diferença apenas marginalmente significativa $(\mathrm{p}=0,1)$ entre as inclinações do tratamento $0 \mathrm{~mL}(\mathrm{~b}=0,82)$ e $40 \mathrm{~mL}(\mathrm{~b}=0,46)$.

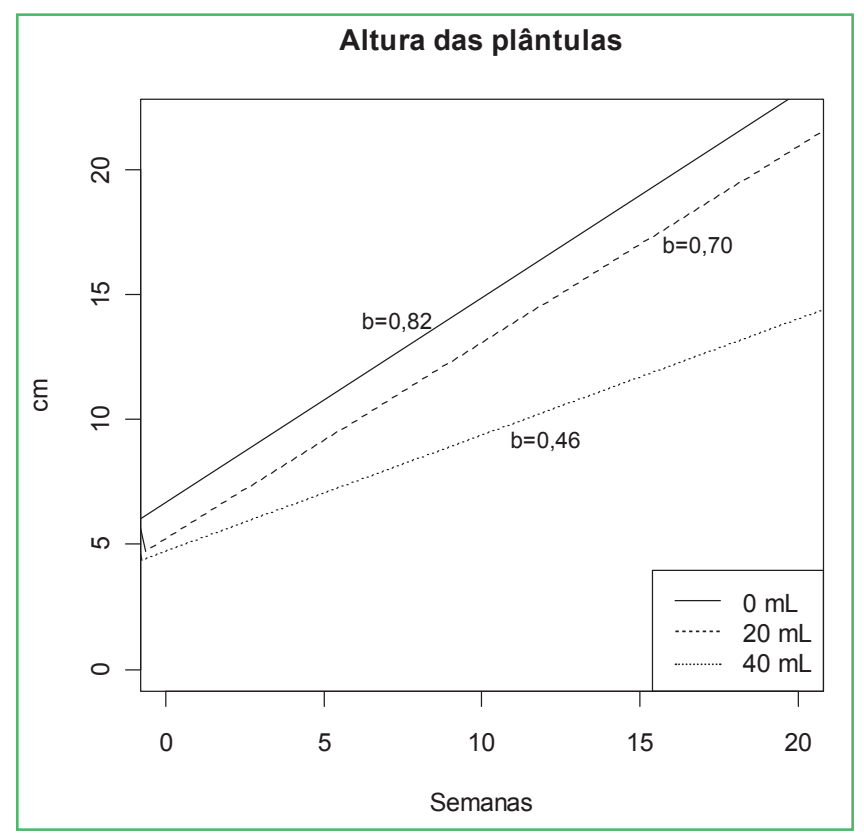

\section{Diâmetro}

As plântulas do tratamento controle apresentaram valores de diâmetro significativamente superiores às dos demais tratamentos da semana três a 12 e da semana 17 até o final do experimento (semana 20) (Figura 3). 
FIGURA 3: Diâmetro (em mm) de plântulas de L. racemosa ( \pm erro padrão) em função dos seis tratamentos experimentais (de 0 até $50 \mathrm{~mL}$ de óleo bunker derramado) e do tempo em semanas. A legenda mostra a concentração de óleo dos tratamentos em uma escala de cores, desde o controle $(0 \mathrm{~mL})$ em rosa claro até a maior concentração $(50 \mathrm{~mL})$ em preto.

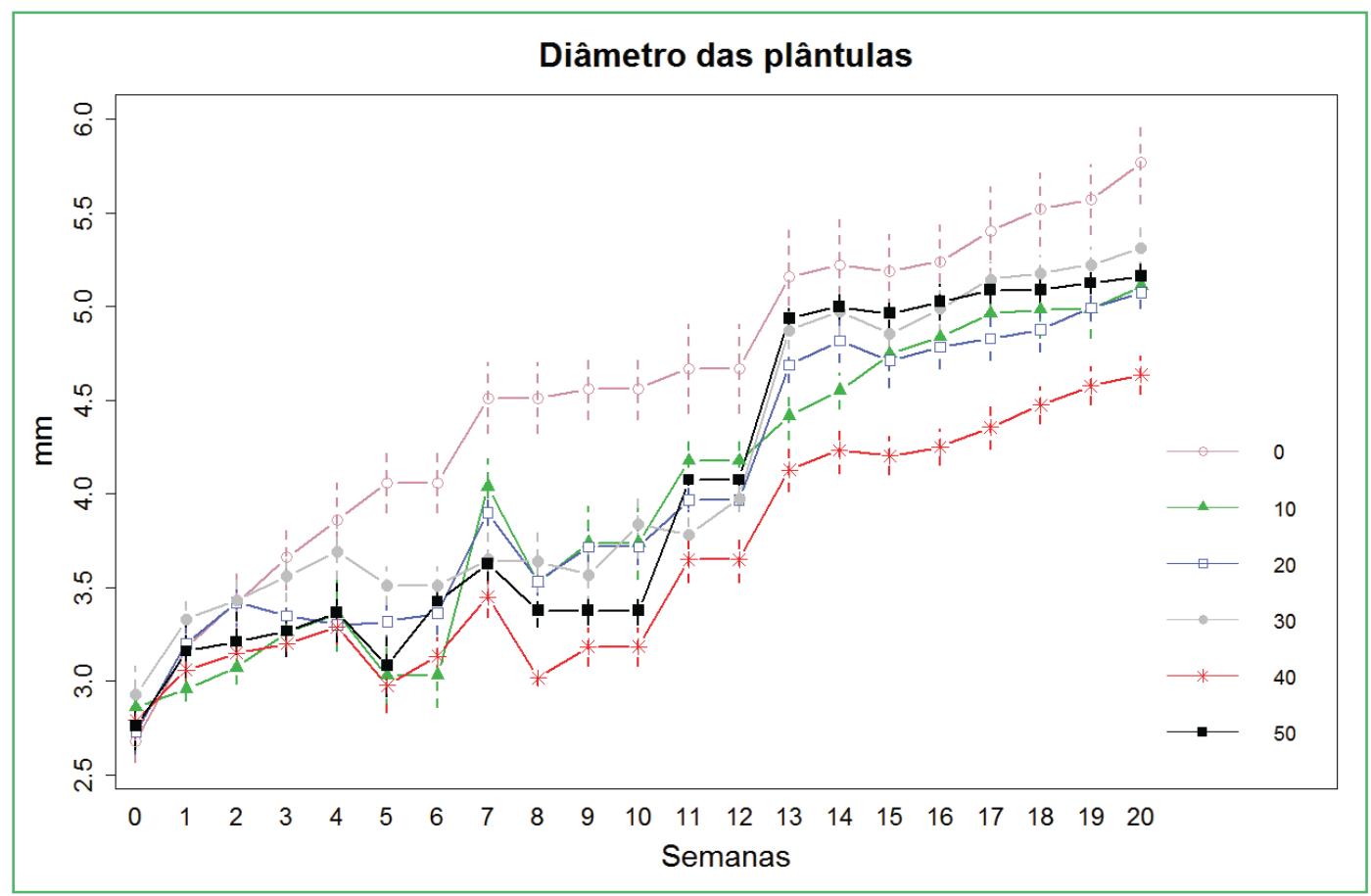

As plântulas dos tratamentos 10 e $20 \mathrm{~mL}$ tiveram diâmetro significativamente superior às dos tratamentos de maior concentração na semana sete e nas semanas nove e 10 . Da semana 11 até a 17 as plântulas do tratamento $50 \mathrm{~mL}$ tiveram pico de crescimento em diâmetro, porém esse crescimento não foi mantido e apresentou queda nas semanas seguintes.

A Figura 4 apresenta os ajustes lineares dos três tratamentos escolhidos. Apesar de existir uma queda do valor de $b$ desde o controle $(0 \mathrm{~mL})$ até a concentração mais alta $(40 \mathrm{~mL})$, estas diferenças não são significativas.

\section{Produção de folhas}

O número de folhas foi significativamente superior nas plântulas dos tratamentos controle e $10 \mathrm{~mL} \mathrm{em}$ comparação com as dos tratamentos 40 e $50 \mathrm{~mL}$ a partir da segunda semana (Figura 5). Nas plântulas do tratamento $20 \mathrm{~mL}$ o número de folhas foi superior às dos tratamentos de maior concentração da semana sete até a nove e da semana 12 até 20. Após as primeiras oito semanas, o controle apresentou perda de folhas
FIGURA 4: Ajustes lineares dos diâmetros das plântulas (em mm) de L. racemosa em três dos tratamentos experimentais. A figura mostra ambos os eixos escalonados em zero para melhor demonstrar a diferença de inclinação da reta (b) entre os tratamentos de $0 \mathrm{~mL}$ (controle), 20 $\mathrm{mL}$ e $40 \mathrm{~mL}$. Não houve diferenças significativas entre as inclinações da reta $(p>0,1)$.

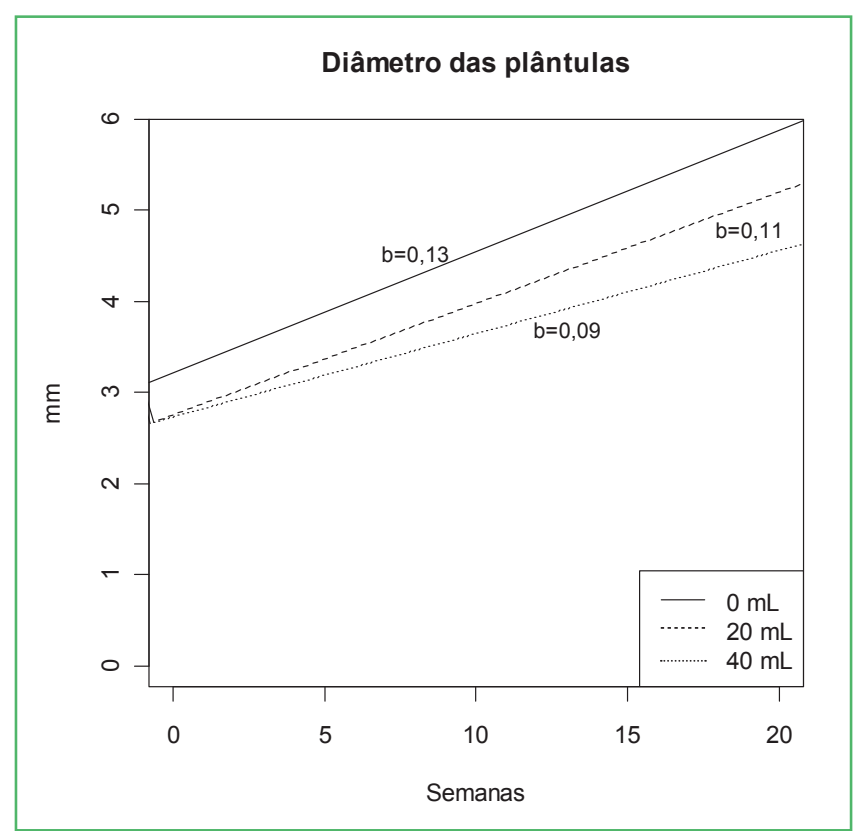


FIGURA 5: Número de folhas em plântulas de L. racemosa ( \pm erro padrão) em função dos seis tratamentos experimentais (de 0 até $50 \mathrm{~mL}$ de óleo bunker derramado) e do tempo em semanas. A legenda mostra a concentração de óleo dos tratamentos em uma escala de cores, desde o controle $(0 \mathrm{~mL})$ em rosa claro até a maior concentração $(50 \mathrm{~mL})$ em preto.

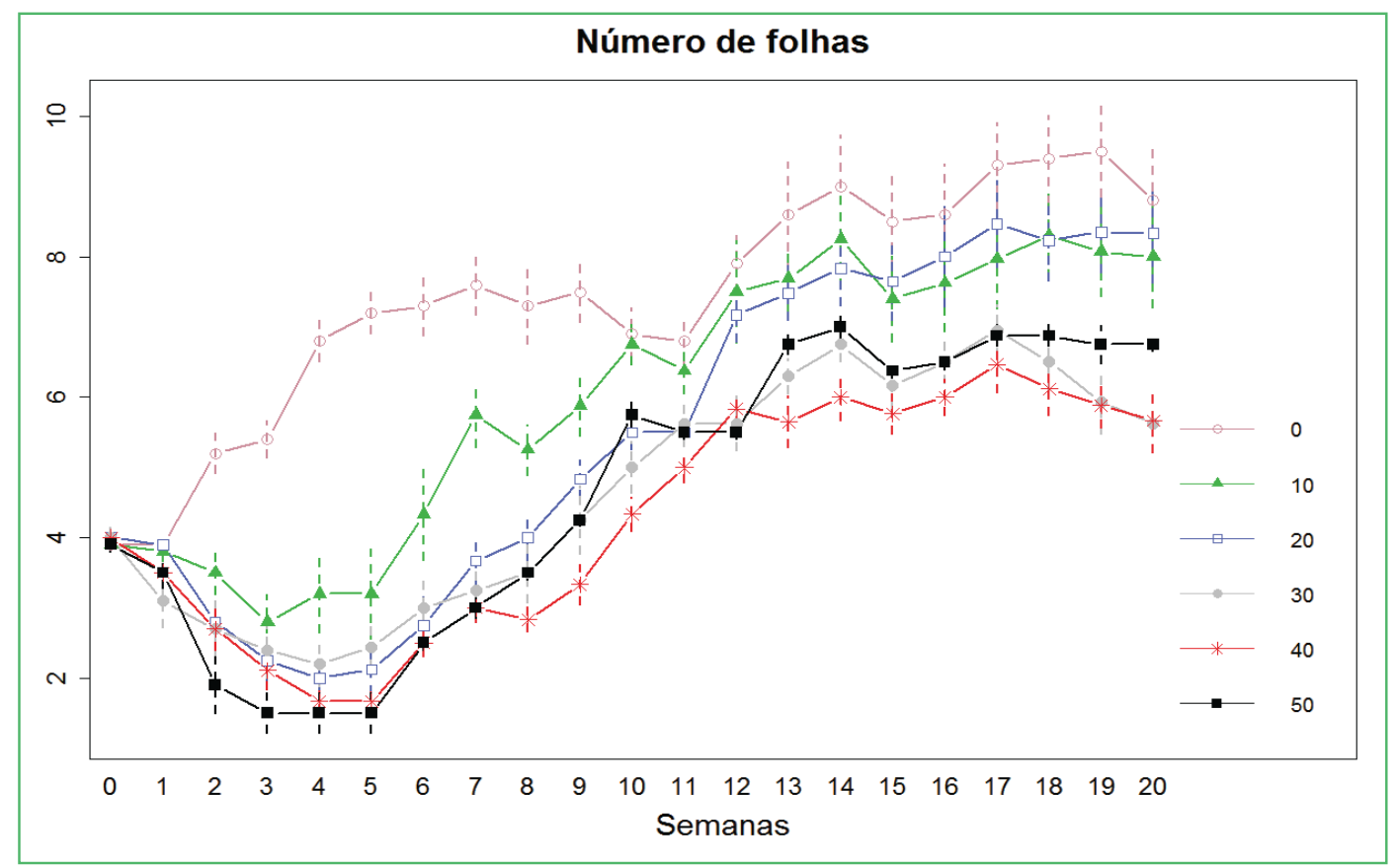

semelhante ao padrão natural (comparável àqueles das demais plântulas em crescimento no viveiro). A partir da semana nove a perda de folhas de todos os vegetais sobreviventes ocorreu em número reduzido e relativamente constante.

Os ajustes lineares dos tratamentos escolhidos mostraram (Figura 6), mais uma vez, maiores inclinações no controle e no tratamento de menor concentração (20 $\mathrm{mL}$ ) em relação aos demais, porém as diferenças não foram significativas estatisticamente.

\section{Comprimento e largura de folhas}

O comprimento das folhas foi significativamente superior nas plântulas do tratamento controle em comparação com o dos tratamentos 40 e $50 \mathrm{~mL}$ da semana dois até a sete (Figura 7). Os ajustes lineares dos tratamentos selecionados mostraram baixas declividades (Figura 8).

As plântulas do controle apresentaram largura das folhas significativamente superior às dos tratamentos 40 e $50 \mathrm{~mL}$ nas semanas quatro e cinco, da semana sete a 12 e da semana 15 em diante (Figura 9).
FIGURA 6: Ajustes lineares do número de folhas $(\mathrm{em} \mathrm{cm})$ de plântulas de L. racemosa em três dos tratamentos experimentais. A figura mostra ambos os eixos escalonados em zero para melhor demonstrar a diferença de inclinação da reta (b) entre os tratamentos de $0 \mathrm{~mL}$ (controle), $20 \mathrm{~mL}$ e $40 \mathrm{~mL}$. Não houve diferenças significativas entre as inclinações da reta $(\mathrm{p}>0,1)$.

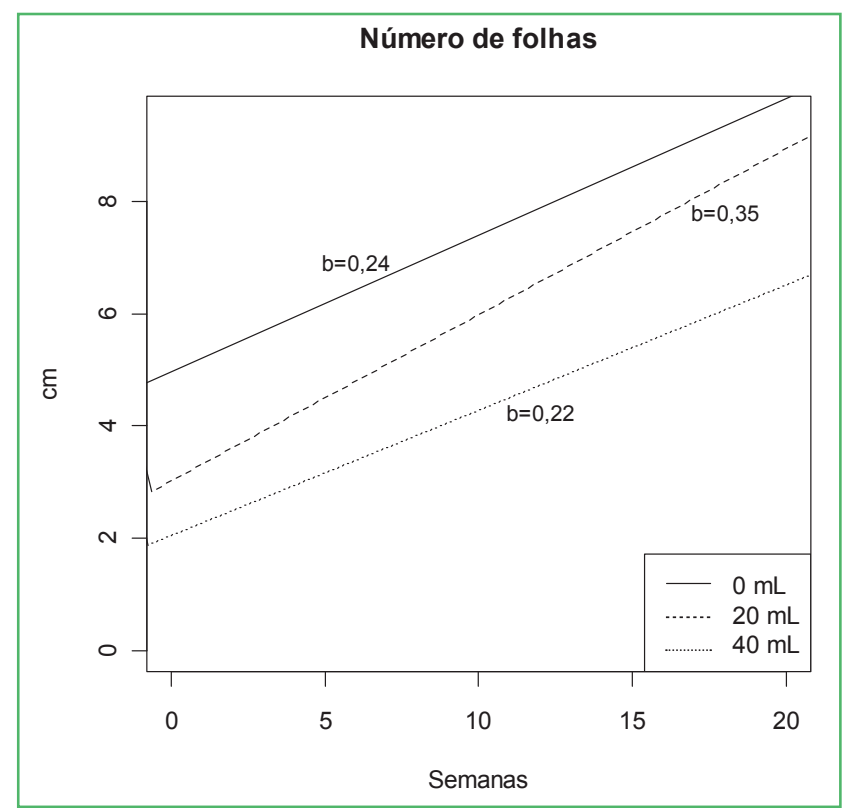


FIGURA 7: Comprimento das folhas (em cm) de plântulas de L. racemosa ( \pm erro padrão) em função dos seis tratamentos experimentais (de 0 até $50 \mathrm{~mL}$ de óleo bunker derramado) e do tempo em semanas. A legenda mostra a concentração de óleo dos tratamentos em uma escala de cores, desde o controle $(0 \mathrm{~mL})$ em rosa claro até a maior concentração $(50 \mathrm{~mL})$ em preto.

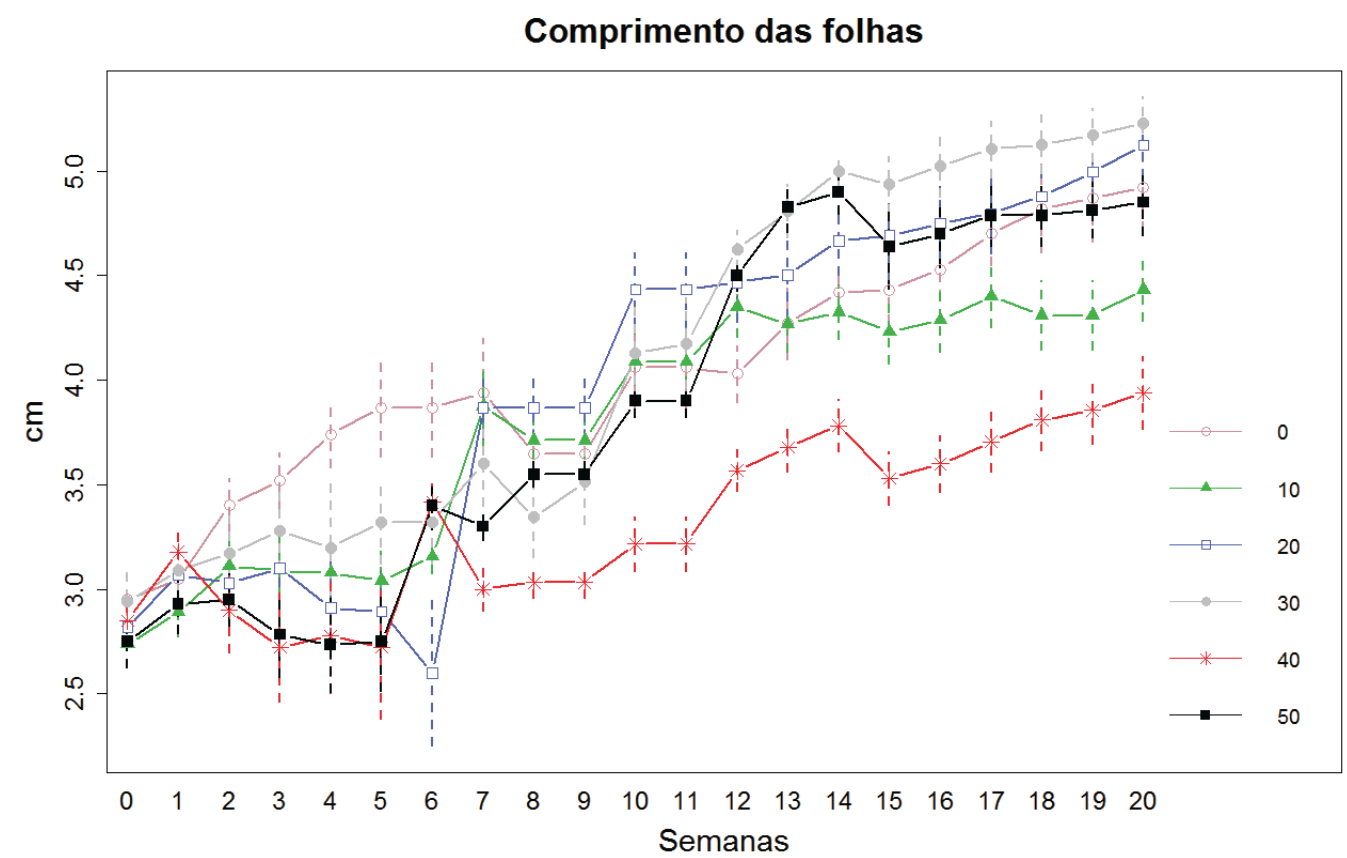

FIGURA 8: Ajustes lineares do comprimento das folhas $(\mathrm{em} \mathrm{cm})$ de plântulas de L. racemosa em três dos tratamentos experimentais. A figura mostra ambos os eixos escalonados em zero para melhor demonstrar a diferença de inclinação da reta (b) entre os tratamentos de $0 \mathrm{~mL}$ (controle), $20 \mathrm{~mL}$ e $40 \mathrm{~mL}$. Não houve diferenças significativas entre as inclinações da reta $(\mathrm{p}>0,1)$.

\section{Comprimento das folhas}

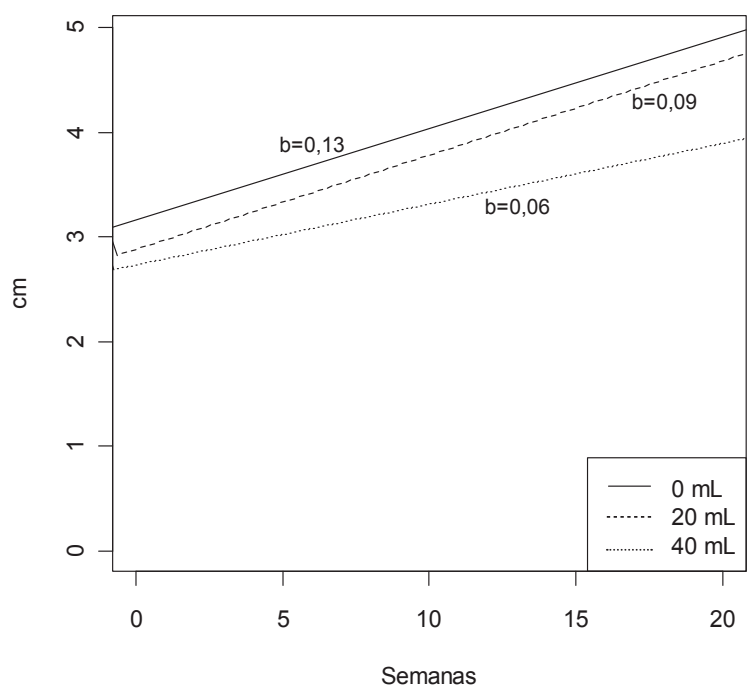

As plântulas do tratamento $50 \mathrm{~mL}$ superaram as do controle em largura nas semanas 13 e 14, mas não mantiveram este crescimento e as dos tratamentos de maior concentração foram superiores ao controle em comprimento a partir da semana 10. As plântulas dos tratamentos de maior concentração apresentaram folhas mais finas e compridas que as dos tratamentos de menor concentração. 
FIGURA 9: Largura das folhas (em cm) de plântulas de L. racemosa ( \pm erro padrão) em função dos seis tratamentos experimentais (de 0 até $50 \mathrm{~mL}$ de óleo bunker derramado) e do tempo em semanas. A legenda mostra a concentração de óleo dos tratamentos em uma escala de cores, desde o controle $(0 \mathrm{~mL})$ em rosa claro até a maior concentração $(50 \mathrm{~mL})$ em preto.

\section{Largura das folhas}

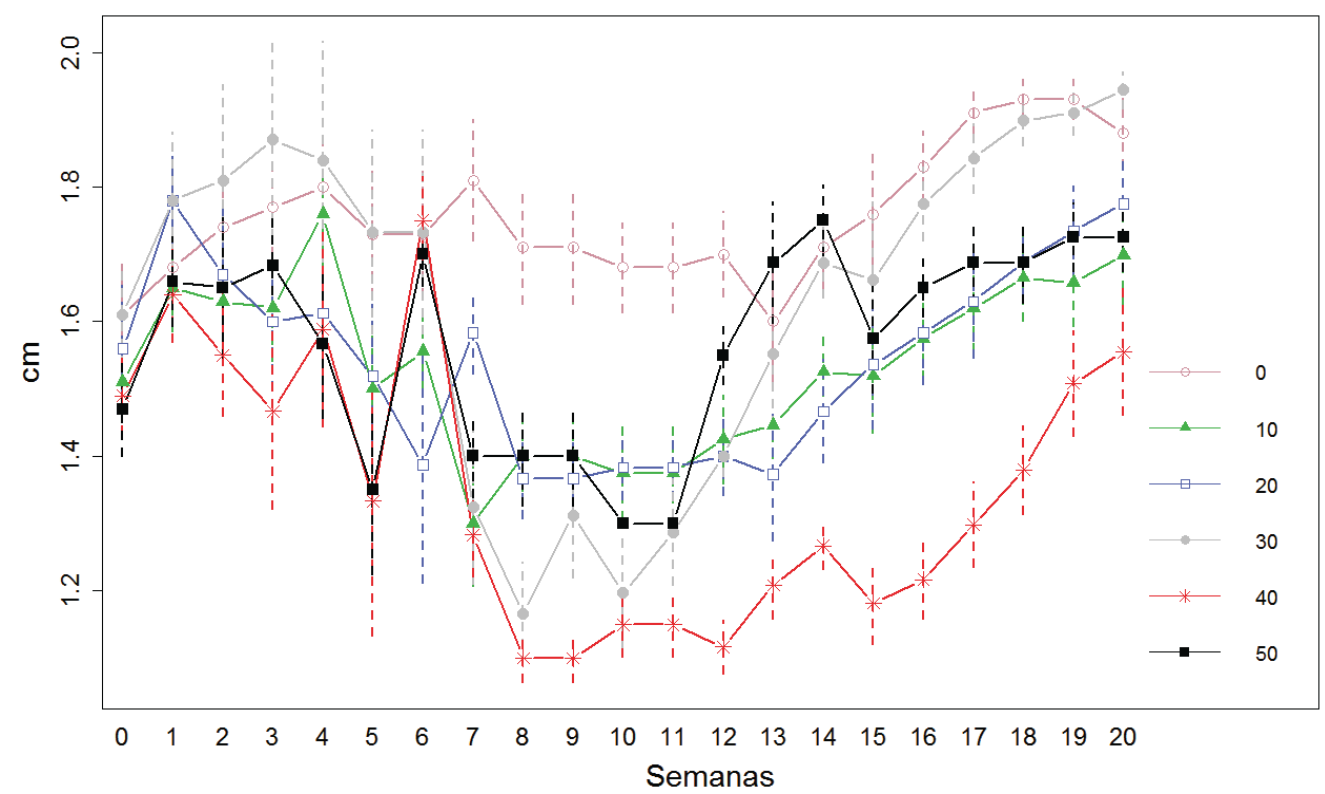

\section{Aspecto das folhas}

Nas primeiras três semanas, ocorreu maior número de folhas amareladas (Figura 10). No final da primeira semana, 13 plântulas apresentavam pelo menos uma folha amarelada, principalmente nos tratamentos $40 \mathrm{e}$ $50 \mathrm{~mL}$, número que dobrou na segunda semana.

O número de folhas amareladas e murchas foi significativamente maior nas plântulas de todos os tratamentos nas primeiras oito semanas (exceto na semana quatro para folhas amareladas) do que no controle. Todas as folhas grudadas pelo óleo, ou com coloração mais escura que o normal ou amarelada, murcharam e caíram das plantas ou, devido ao ressecamento dos pecíolos, caíram antes de murchar.

\section{Nível de vitalidade}

O nível de vitalidade das plântulas do controle se manteve significativamente superior ao de todos os outros tratamentos durante todo o experimento, com maior altura e aspecto do caule e folhas muito mais saudáveis que os demais tratamentos (Figura 11). As plântulas do tratamento $10 \mathrm{~mL}$ apresentaram nível de vitalidade significativamente superior às do tratamento $50 \mathrm{~mL}$ durante todo o experimento e também significativamente superior às plântulas do tratamento $40 \mathrm{~mL}$ da primeira semana até a 11 e na semana 20.

A observação dos tratamentos de maior concentração (40 e $50 \mathrm{~mL}$ ) nas figuras relacionadas com as folhas e na figura do nível de vitalidade confirma a eficiência do nível de vitalidade em ilustrar as condições de vida das plântulas.

Da semana três até a oito, quando houve maior prejuízo às folhas, o nível de vitalidade das plântulas dos tratamentos de maior concentração registrou valores baixos, ainda mais distantes dos valores do tratamento controle. Nos meses seguintes, com a recuperação destas plântulas, o nível de vitalidade voltou a subir. 
FIGURA 10: Número de folhas amareladas em plântulas de L. racemosa ( \pm erro padrão) em função dos seis tratamentos experimentais (de 0 até $50 \mathrm{~mL}$ de óleo bunker derramado) e do tempo em semanas. A legenda mostra a concentração de óleo dos tratamentos em uma escala de cores, desde o controle $(0 \mathrm{~mL})$ em rosa claro até a maior concentração $(50 \mathrm{~mL})$ em preto.

\section{Folhas amareladas}

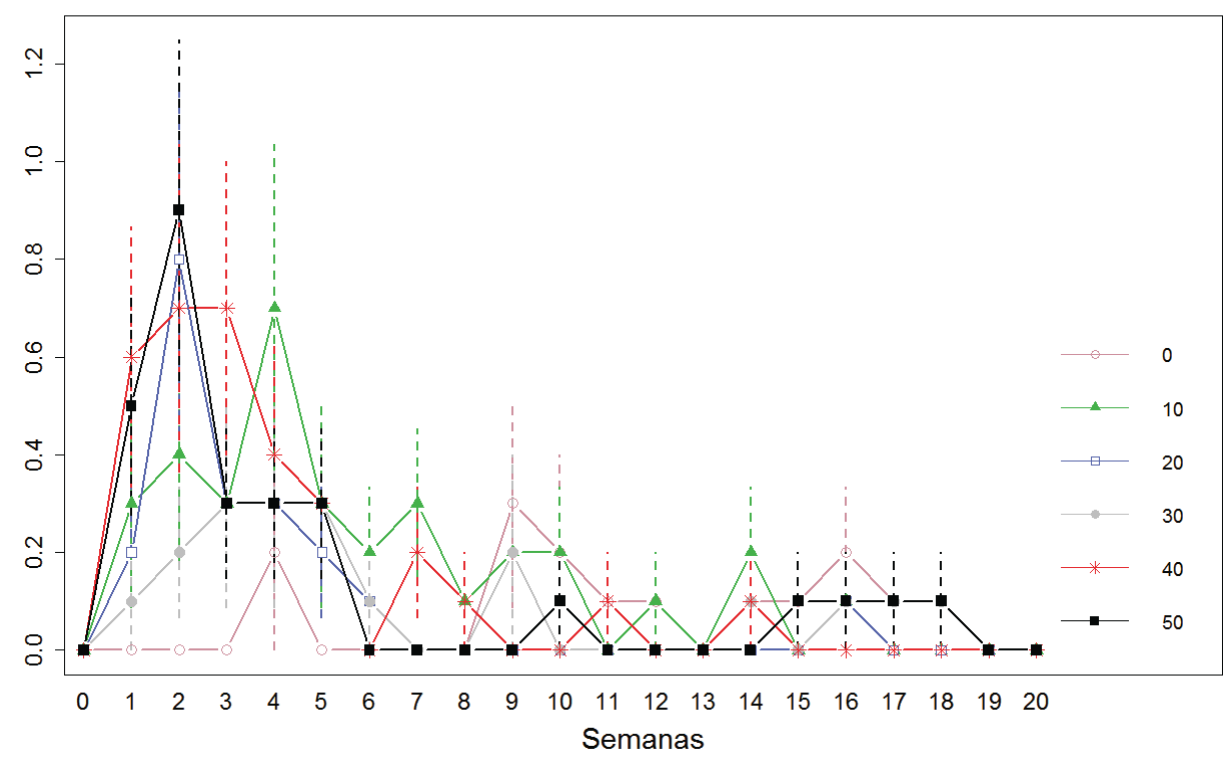

FIGURA 11: Nível de Vitalidade (NV) de plântulas de L. racemosa ( \pm erro padrão) em função dos seis tratamentos experimentais (de 0 até $50 \mathrm{~mL}$ de óleo bunker derramado) e do tempo em semanas. A legenda mostra a concentração de óleo dos tratamentos em uma escala de cores, desde o controle $(0 \mathrm{~mL})$ em laranja, até a maior concentração $(50 \mathrm{~mL})$ em preto.

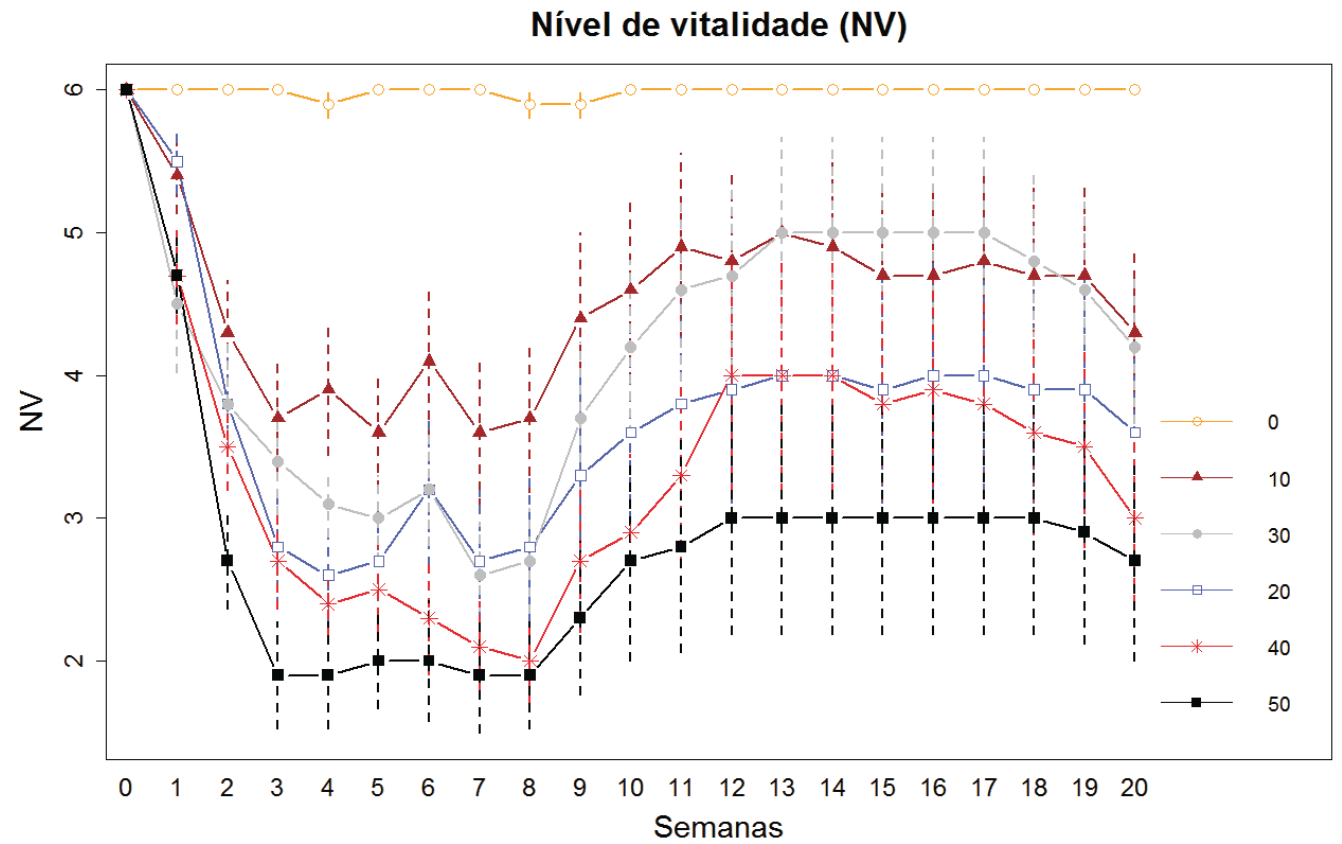


TABELA 3: Coeficiente angular de regressão (b) e coeficiente de determinação $\left(\mathrm{r}^{2}\right)$ para cada um dos seis tratamentos experimentais $(0 \mathrm{~mL}$ a $50 \mathrm{~mL}$ de óleo $)$ para aquelas variáveis que apresentaram relações lineares. ns: nãosignificativa.

\begin{tabular}{|c|c|c|c|c|c|}
\hline \multicolumn{3}{|c|}{ Altura da plântula } & \multicolumn{3}{|c|}{ Diâmetro da plântula } \\
\hline $\mathrm{mL}$ de óleo bunker & $\mathrm{B}$ & $\mathrm{r}^{2}$ & $\mathrm{~mL}$ de óleo bunker & $\mathrm{b}$ & $\mathrm{r}^{2}$ \\
\hline 0 & 0,82 & 0,96 & 0 & 0,13 & 0,94 \\
\hline 10 & 0,78 & 0,94 & 10 & 0,12 & 0,94 \\
\hline 20 & 0,70 & 0,94 & 20 & 0,11 & 0,92 \\
\hline 30 & 0,67 & 0,95 & 30 & 0,12 & 0,88 \\
\hline 40 & 0,46 & 0,96 & 40 & 0,09 & 0,87 \\
\hline 50 & 0,65 & 0,95 & 50 & 0,13 & 0,88 \\
\hline Comprimento das folhas & & & Número de folhas & & \\
\hline $\mathrm{mL}$ de óleo bunker & $\mathrm{B}$ & $\mathrm{r}^{2}$ & $\mathrm{~mL}$ de óleo bunker & B & $\mathrm{r}^{2}$ \\
\hline 0 & 0,09 & 0,92 & 0 & 0,24 & 0,83 \\
\hline 10 & 0,09 & 0,87 & 10 & 0,29 & 0,87 \\
\hline 20 & 0,13 & 0,88 & 20 & 0,35 & 0,84 \\
\hline 30 & 0,13 & 0,93 & 30 & 0,23 & 0,75 \\
\hline 40 & 0,06 & 0,79 & 40 & 0,22 & $0,70^{\text {ns }}$ \\
\hline 50 & 0,13 & 0,90 & 50 & 0,19 & 0,76 \\
\hline
\end{tabular}

\section{Discussão}

\section{Efeitos letais e subletais}

Neste estudo, a divisão dos efeitos do derrame de óleo em plântulas do mangue em duas fases, como descritas por Lewis (1983), ficou bastante visível nas figuras. Efeitos como o aparecimento de folhas amareladas, perda de folhas e consequente morte das plântulas, registrados também por Grant et al. (1993), Proffit et al. (1995) e NOAA (2002), respectivamente, ocorreram principalmente nas primeiras semanas e por isso são considerados efeitos agudos.

Os prejuízos ao crescimento e produção de folhas, descritos também por Proffit e Devlin (1998), ocorreram mais intensamente após o primeiro mês e por isso são definidos como efeitos crônicos. Os efeitos agudos ou letais se manifestaram principalmente nos primeiros 30 dias após o derrame, fase em que ocorreu a maior parte das mortes, enquanto os efeitos crônicos ou subletais ocorreram meses após o derrame, quando os prejuízos ao crescimento foram observados, assim como em Lewis (1983).

\section{Efeitos do óleo bunker}

O óleo bunker, como a maioria dos óleos densos, recobriu o sedimento, caule, folhas, pneumatóforos e em algumas plântulas fez com que as folhas grudassem umas nas outras, dificultando de várias maneiras as trocas gasosas e a fotossíntese (PEZESHKI et al., 2000).

Apesar da reduzida capacidade de penetrar e intoxicar (NOAA, 2003), o óleo bunker causou grande mortalidade nas plântulas dos tratamentos de maior concentração, resultado comparável ao estudo de Duke et al. (2000).

Os efeitos agudos foram causados não apenas pela toxicidade imediata e pela presença dos hidrocarbonetos policíclicos aromáticos que danificam tecidos das plântulas, mas também pelo estresse e possível dificuldade para realizar a fotossíntese e trocas gasosas satisfatórias com o ambiente (NRC, 2003).

Quando a morte não é imediata (na primeira semana), os efeitos do óleo se traduzem na redução na qualidade das folhas, em alguns casos até mesmo do caule, o que pode posteriormente causar a morte ou efeitos crônicos (NOAA, 2002). 


\section{A importância das follhas}

Assim como em Pezeshki et al. (2000), as pequenas folhas em desenvolvimento (folhas novas) demonstraram vital importância para as plântulas, pois substituíram aquelas perdidas nas primeiras semanas após o contato com óleo.

Além das folhas novas, algumas plântulas atingidas por óleo contaram com a permanência dos cotilédones por mais tempo que o normal, os quais podem servir como fonte de alimento adicional diante da impossibilidade de realizar satisfatoriamente a fotossíntese enquanto as folhas estão impregnadas por óleo.

\section{Efeitos dos tratamentos}

As plântulas dos tratamentos de maior concentração (especialmente $50 \mathrm{~mL}$ ) apresentaram folhas amareladas em maior número nas primeiras quatro semanas, as quais murcharam e caíram nas semanas três até a cinco (incluindo cotilédones e folhas novas) de forma tão intensa que impediram a recuperação da maioria dessas plântulas e, junto com a atrofia do caule causaram as mortes observadas entre as semanas 3 a 6 , resultados comparáveis ao estudo de Geo-Marine Inc. (2000).

As plântulas que conseguiram sobreviver às primeiras sete semanas após o contato com óleo (em sua maioria pertencente aos tratamentos de menor concentração) permaneceram vivas até o final do experimento, com crescimento e qualidade muito inferiores ao controle (exceto $10 \mathrm{~mL}$ ), mas, devido à sua capacidade de adaptação, recuperaram a vitalidade na medida em que a água das regas "lavou" as folhas e o sedimento.

O processo de "lavagem" das folhas e sedimento pela rega (semelhante ao que ocorre na natureza pela água das marés) carregou os componentes leves e mais tóxicos do óleo para fora dos sacos de muda, enquanto as folhas atingidas por óleo foram substituídas por novas e a atrofia do caule, quando presente, corrigida por abscisão.

A sobrevivência de todas as plântulas do controle até o final do experimento é comparável aos resultados descritos por Grant et al. (1993), enquanto no tratamento
$10 \mathrm{~mL}$ as plântulas sobreviventes apresentaram os maiores valores médios quando comparados com os outros tratamentos, ou seja, embora as mortes tenham ocorrido de forma muito parecida entre os tratamentos (exceto $50 \mathrm{~mL}$ ), os efeitos crônicos como prejuízos ao crescimento se manifestaram mais intensamente em função do aumento da concentração de óleo.

Enquanto nas plântulas do tratamento controle, onde não houve mortes, as variáveis medidas apresentaram valores crescentes com o tempo, nas plântulas dos tratamentos onde as mortes ocorreram mais intensamente as variáveis apresentaram queda pronunciada.

As plantas sobreviventes do tratamento $50 \mathrm{~mL}$ apresentaram pico de crescimento em comprimento e largura das folhas e diâmetro nas semanas 13 a 15 demonstrando a capacidade de recuperação e adaptação destes vegetais após o impacto dos primeiros meses, porém este crescimento não foi mantido, ou seja, não acompanhou na mesma proporção as plântulas do controle nas semanas seguintes.

Assim como em Wardrop et al. (1996), a tendência para todas as variáveis foi de decréscimo em função do aumento da concentração de óleo. Essa tendência foi quebrada para o tratamento $50 \mathrm{~mL}$, pois apenas três plantas deste tratamento sobreviveram e estas apresentavam folhas saudáveis (embora os demais aspectos não fossem comparáveis às plântulas do controle).

A presença de folhas com maior comprimento e menor largura em comparação com as demais plântulas nos tratamentos de maior concentração pode ser mais um dos efeitos causados pelo contato entre o óleo e estas.

Embora as plântulas do tratamento $10 \mathrm{~mL}$ tenham se mantido significativamente superiores às dos tratamentos 40 e $50 \mathrm{~mL}$ em crescimento $\mathrm{e}$ vitalidade durante a maior parte do experimento, a comparação das variáveis, principalmente do nível de vitalidade entre as plântulas do controle e do tratamento $10 \mathrm{~mL}$ demonstra que mesmo em concentrações pequenas os efeitos crônicos do óleo bunker são significativos. 


\section{Nivel de vitalidade}

A criação da escala de qualidade tornou possível não apenas resumir e concentrar os resultados de todas as variáveis em apenas uma de maneira eficiente, mas também confirmar as tendências do impacto por meio da observação dos aspectos gerais do vegetal no viveiro.

A figura do nível de vitalidade evidencia a intensa mortalidade das primeiras semanas, a recuperação das plântulas sobreviventes meses depois, a proporcionalidade entre os efeitos crônicos e a concentração de óleo e principalmente a superioridade do controle em vitalidade.

Ao confrontar as figuras de todas as variáveis com a figura do nível de vitalidade é possível perceber que as plântulas do controle foram absolutas em qualidade durante todo o experimento e que o nível de vitalidade foi um instrumento visual importante, que traduziu com eficiência a evolução das variáveis dependentes em função dos fatores neste estudo, embora novos testes sejam necessários para aperfeiçoá-la, dada a complexidade das respostas das plantas nas diferentes fases do seu desenvolvimento.

Para pesquisas futuras sugerem-se estudos detalhados da presença e estados das folhas novas e cotilédones durante a observação dos efeitos de derrames e testes envolvendo a escala de qualidade. Sugerem-se também derrames crônicos de óleo bunker em plântulas de Laguncularia racemosa e derrames agudos e crônicos em outras plantas de mangue, para possibilitar a comparação das diferenças dos efeitos deste tipo de óleo em diferentes plantas e em diferentes tipos de derrames, comparações para as quais os dados deste estudo poderão ser úteis.

\section{Referências}

BRITO, E. M. S.; DURAN, S.; GUYONEAUD, R.; URRIZA, M. G.; OTEYZA, T. G.; CRAPEZ, M. A. C.; ALELUIA, I.; WASSERMAN, J. C. A. A case study of in situ oil contamination in a mangrove swamp (Rio de Janeiro, Brazil). Marine Pollution Bulletin, Amsterdam, v. 58, p. 418-423, 2009.

BURNS, K. A.; SIMMONS, L. Y. The Galeta Oil Spill. IV. Relationship Between Sediment and Organism Hydrocarbon Loads. Estuarine, Coastal and Shelf Science, New York, v. 38, p. 397-412, 1994.
DUKE, N. C.; BURNS, K. A.; SWANNELL, R. P. J.; DALHAUS, O.; RUPP, R. J. Dispersant use and a bioremediation strategy as alternate means of reducing impacts of large oil spills on mangroves: The Gladstone field trials. Marine Pollution Bulletin, Amsterdam, v. 41, p. 403-412, 2000.

GEO-MARINE, INC. Natural resource damage assessment for a JP-5 fuel spill at Naval Station Roosevelt Roads, Puerto Rico. Draft final report. Norfolk: Commander, Atlantic Division, Naval Facilities Engineering Command, 2000. 58 p.

GRANT, D. L.; CLARKE, P. J.; ALLAWAY, W. G. The response of grey mangrove (Avicennia marina) seedlings to spills of crude oil. Journal of Experimental Marine Biology and Ecology, Amsterdam, v. 171, p. 273- 295, 1993.

IMBERT, D.; ROUSTEAU, A.; SCHERRER, P. Ecology of mangrove growth and recovery in the Lesser Antilles: state of knowledge and basis for restoration projects. Restoration Ecology, Crawley, v. 8, n. 3, p. 230-236, 2000.

LEWIS, R. R. Impact of oil spills on mangrove forests. Tasks for Vegetation Science, Haia, v. 8, p. 171-183, 1983.

LEWIS, R. R. Ecological engineering for successful management and restoration of mangrove forests. Ecological Engineering, Columbus, v. 24, p. 403-418, 2005.

NOAA - NATIONAL OCEANIC AND ATMOSPHERIC ADMINISTRATION. Oil spills in mangroves: planning \& response considerations. Seattle, Washington: U.S. Department of commerce, $2010.70 \mathrm{p}$.

NOAA - NATIONAL OCEANIC AND ATMOSPHERIC ADMINISTRATION. An introduction to coastal habitats and biological resources for oil spill responses. Seattle, Washington: U.S. Department of commerce. 2003. 75 p.

NRC - NATIONAL RESEARCH COUNCIL. Oil in the sea. III: Inputs, fate and effects. Washington: The National Academies Press, 2003. 122 p.

NUDI, A. H.; WAGENER, A. L. R.; FRANCIONI, E.; SCOFIELD, A. L.; SETTE, C. B.; VEIGA, A. Validation of Ucides cordatus as a bioindicator of oil contamination and bioavailability in mangroves by evaluating sediment and crab PAH records. Environment International, Elmsford, v. 33, p. 315-327, 2007.

PEZESHKI, S. R.; HESTER, M. W.; LIN, Q.; NYMAN J. A. The effects of oil spill and clean-up on dominant US Gulf coast marsh macrophytes: a review. Environmental Pollution, Amherst, v. 108, p. 129-139, 2000.

PROFFITT, C. E.; DEVLIN, D. J. Are there cumulative effects in red mangroves from oil spills during seedling and sapling stages? Ecological Applications, Ithaca, v. 8, n. 1, p. 121-127, 1998.

PROFFITT, C. E.; DEVLIN, D. J.; LINDSEY, M. Effects of oil on mangrove seedlings grown under different environmental conditions. Marine Pollution Bulletin, Amsterdam, v. 30, n. 12, p. 788-793, 1995.

R DEVELOPMENT CORE TEAM. R: A language and environment for statistical computing. 2011. R Foundation for Statistical Computing. Disponível em $<$ http://www.R- project.org $>$. Acesso em: 22 mar. 2011.

SANDRINI-NETO, L.; CAMARGO, M. G. GAD (General ANOVA Design): an R package for ANOVA designs from the general principles. 2011. Disponível em $<$ http://cran.r-project.org/ web/packages $>$. Acesso em: 11 out. 2011. 
SCOTT, R. J.; KNOTT, M. A cluster analysis method for grouping means in the analysis of variance. Biometrics, Washington, n 30 , p. 507-512, 1974.

SOKAL, R. R.; ROHLF, F. J. Biometry: the principles and practice of statistics in biological research. New York: W. H. Freeman and Co., 1995.887 p.

TOUCHETTE, B. W.; STOUT, D. K.; BACA, B. J. Effects of an oil spill in a mangrove mitigation site. In: ANNUAL CONFERENCE ON WETLANDS RESTORATION AND CREATION, 19, 1992, Tampa. Proceedings... Tampa: Hillsborough Community College, Institute of Florida Studies, 1992. p. 213-227

UNDERWOOD, A. J. Experiments in Ecology: their logical design and interpretation using analysis of variance. Cambridge: Cambridge University Press, 1997. 504 p.
VOLKMAN, J. K.; HOLDSWORTH, G. D.; NEILL, G. P.; BAVOR, H. J. Identification of natural, anthropogenic and petroleum hydrocarbons in aquatic sediments. Science of the Total Environment, Amsterdam, v. 112, p. 203-219, 1992.

WANG, Z.; FINGAS, M.; PAGE, D.S. Oil spill identification. Journal of Chromatography A, Tallahassee, v. 834, p. 369-411, 1999.

WARDROP, J. A.; WAGSTAFF, B.; PFENNIG, P.; LEEDER, J.; CONNOLY, R. M. The distribution, persistence and effects of petroleum hydrocarbons in mangroves impacted by the "Era" oil spill (September, 1992). Final Phase One report. Adelaide: South Australian Department of Environment and Natural Resources, 1996. 76 p.

ZAR, J. H. Biostatistical analysis. New Jersey: Prentice Hall, 1996. $662 \mathrm{p}$. 